\title{
O inconfidente que virou santo: estudo biográfico sobre Salvador Carvalho do Amaral Gurgel
}

ADELTO GONÇALVES

\section{O nascimento em Parati}

$\mathrm{Q}$ UANDo Salvador Carvalho do Amaral Gurgel nasceu, a vila de Parati, na comarca do Rio de Janeiro, em frente ao Oceano Atlântico, já era, como hoje, um povoado formado por um casario baixo à beira de um cais de pedra. ${ }^{1}$ Estava situado na extremidade de um longo braço de mar pontilhado por numerosas ilhotas povoadas de palmeiras.

Abrigaria pouco mais de três mil moradores e não teria mais de uma dúzia de ruas direitas entrecruzadas retamente, com boas casas de pedras, ornadas com uma igreja matriz da invocação de Nossa Senhora dos Remédios e as capelas de Nossa Senhora do Rosário das Dores e de Santa Rita. ${ }^{2}$

Foi num dia de verão, em 16 de fevereiro de 1762, que nasceu Salvador. Era filho natural do capitão-mor Salvador Carvalho Cunha do Amaral Gurgel, descendente de Francisco Amaral Gurgel, fazendeiro e potentado da Parati dos primeiros anos, comandante de numerosas tropas que abasteciam Minas Gerais, especialmente Vila Rica e os povoados da região de Rio das Mortes, ao sul da capitania.

A mãe, Domiciliana de Jesus, quando Salvador nasceu, era amante do capitão-mor. Foi só depois da morte de sua primeira mulher que o capitão-mor uniu-se legalmente a Domiciliana. Do primeiro casamento, o capitão trazia outro filho: José Antônio Campos do Amaral Gurgel, que haveria de subir a áspera serra para radicar-se em Taubaté e, como o irmão, virar cirurgião. ${ }^{3}$

Salvador cresceu na vila de Parati amparado pelas boas relações familiares. $\mathrm{Na}$ Parati daqueles anos, corria um comércio amplo que consistia na permuta das mercadorias que baixavam de Minas Gerais e São Paulo ou subiam de Santos, por outras que vinham da Europa. Mas a preferência era para o sal, trazido de Pernambuco por embarcações que, em troca, levavam farinha e outros mantimentos.

A riqueza, porém, ficava nas mãos de bem poucos, que exploravam e mantinham em dependência os que produziam os frutos da terra. ${ }^{4}$ Com certeza, o pai de Salvador estava entre essas principais pessoas. Sabe-se que o capitão-mor era "sujeito muito zeloso", que se preocupava em "coligir e conservar memórias 
e manuscritos úteis". ${ }^{5}$ Talvez não fosse tão abastado a ponto de reunir condições para mandar os filhos estudarem medicina em Coimbra ou em Montpellier, na França, como faziam as famílias mais ricas de seu tempo.

\section{A vida no Rio de Janeiro}

Logo, Salvador preferiu deixar a família em Parati e, de barco, subiu o litoral rumo ao norte, até o Rio de Janeiro. Corria o ano de 1787 quando, aos 25 anos de idade, tirou a carta de praticante de cirurgia. Era um jovem de olhos pretos, cabelos castanhos, cinco pés por cinco polegadas $(1 \mathrm{~m} \mathrm{e} 65 \mathrm{~cm}$ ) de altura e solteiro. ${ }^{6}$

No Rio de Janeiro, capital do vice-reinado, Salvador deve ter levado vida um tanto despreocupada. Meteu-se em alguma confusão porque acabou compelido a buscar segurança em Minas Gerais, perseguido que era pelo ouvidor, o desembargador Francisco Luís Álvares da Rocha, ${ }^{7}$ com quem haveria de cruzar outra vez, anos mais tarde, ao ser acusado de envolvimento na projetada sublevação de $1789 .{ }^{8}$ Foi morar em Vila Rica, em princípio, na casa do doutor Antônio José Soares de Castro, tenente-coronel do regimento dos pardos de Vila do Príncipe. ${ }^{9}$ E arrumou emprego como praticante de cirurgia no regimento da tropa paga.

\section{A Vila Rica de 1787}

Quando Salvador chegou a Vila Rica, naquele mesmo ano de 1787, a capitania de Minas Gerais passava por tempos de instabilidade política. O governador e capitão-general Luís da Cunha Meneses andava às turras com o ouvidorgeral Tomás Antônio Gonzaga, o futuro poeta de Marília de Dirceu. Cada um representava um grupo de interesses.

Desde que chegara em meados de 1783, Cunha Meneses vinha cumprindo paulatinamente uma política de substituição dos naturais da terra por reinóis nos principais cargos militares. No quartel principal da Demarcação Diamantina, no Tijuco, o capitão José de Vasconcelos Parada e Sousa, reinol, era quem comandava a tropa paga.

Ao final de 1786, o tenente José de Sousa Lobo e Melo, também reinol, assumira o comando do destacamento da Serra Diamantina de Santo Antônio de Itacambiruçu, em substituição ao capitão Baltasar José Mairinque, pai da futura noiva do ouvidor Gonzaga, Maria Dorotéia Joaquina de Seixas. O quartel de Itacambiruçu era subordinado ao do Tijuco, mas ambos eram os mais importantes entre os seis destacamentos que zelavam pela ordem na capitania.

Os dois militares eram homens fiéis ao governador e, desde o início do governo, haviam entrado em atrito com as autoridades da Demarcação Diamantina, um território sob a administração direta de Lisboa, que aspirava a ampla autonomia em relação à capitania. Essa independência, porém, nem sempre ficou clara porque o capitão-general nunca a reconheceu.

Por trás de tudo, o que estava em jogo eram o contrabando de diamantes 
e a sonegação fiscal. As autoridades da Demarcação, como o intendente do ouro Antônio Barroso Pereira, o intendente dos diamantes José Antônio Meireles Freire, vulgo Cabeça de Ferro, e o fiscal dos diamantes Luís Beltrão de Gouveia e Almeida haviam estabelecido relações suspeitas com as famílias poderosas do Tijuco, que sempre haviam lucrado com o extravio de diamantes.

Os militares fiéis a Cunha Meneses viriam a perturbar esses arranjos provincianos em proveito próprio e do governador. Além disso, a pretexto de combater a delinquência, passaram a perseguir e até a matar mineradores e outras pessoas que se recusavam ao trabalho escravo. As determinações do ouvidorgeral e dos desembargadores da Demarcação Diamantina eram derrubadas por uma penada ou mesmo uma ordem verbal do governador.

Muitas vezes, delinquentes acabavam soltos por determinação direta de Cunha Meneses, que teria chegado ao cúmulo de até dar dinheiro aos presos "para os gastos fazerem da fugida". ${ }^{10} \mathrm{O}$ ouvidor Gonzaga era obrigado a assistir a tudo impassível.

Aquele clima de insatisfação entre as famílias mais ricas da capitania acabava também por contagiar os mais humildes, mineradores, pequenos comerciantes e até militares de postos inferiores. Foi por não compactuar com as arbitrariedades de Cunha Meneses e seus acólitos que o alferes Joaquim José da Silva Xavier, 39 anos, acabou afastado do comando do destacamento da Serra da Mantiqueira, ponto-chave de ligação entre Vila Rica e o Rio de Janeiro.

\section{A pregação libertária}

É possível que por essa época já tivesse chegado aos ouvidos do capitãogeneral a pregação libertária que o alferes vinha fazendo desde os primeiros tempos de seu governo. ${ }^{11}$ Cunha Meneses talvez tenha preferido entregar o comando do destacamento a um oficial menos questionador, embora já soubesse que Xavier era considerado uma "inteligência mineralógica" 12 e respeitasse os seus profundos conhecimentos da região. Xavier era também conhecido como Tiradentes em razão de sua habilidade para extrair e fabricar dentes.

Desgostoso por ter sido preterido várias vezes nas promoções assinadas pelo governador, Tiradentes pediu licença de seu regimento em março de 1787 por dois meses e foi para o Rio de Janeiro. ${ }^{13}$ Pretendia viajar para o Reino a fim de tratar de algumas "dependências". Talvez quisesse entrar em contato com as ideias republicanas. Foi em setembro que recebeu autorização da Corte para fazer a viagem. ${ }^{14}$

Até então, renovara várias vezes o pedido de afastamento de sua unidade em Vila Rica. ${ }^{15}$ Mas não deve ter feito a viagem porque, em 1788, apresentou novo pedido de licença para viajar ao Reino sob a alegação de que não pudera fazê-lo em razão de "moléstias e outras causas". A licença só seria assinada pela rainha dona Maria I em agosto de $1788 .^{16}$

No total, o alferes ficaria ausente de seu regimento quase um ano e meio, tempo que aproveitou para encetar algumas iniciativas empresariais no Rio de 
Janeiro, como tentar arrendar oito braças de terrenos na Praia dos Mineiros e seis braças na Praia de Dom Manuel para construir um guindaste de madeira que serviria para o "embarque de animais quadrúpedes e manufaturas", ${ }^{17}$ além de ocupar-se num trapiche em Andaraí ${ }^{18}$ e traçar planos para o abastecimento de água da cidade em substituição ao arcaico sistema de distribuição do líquido em pipas, o que lhe valeu, certa noite, na Casa da Ópera, estrondosas vaias puxadas por aqueles que detinham o monopólio desse serviço. ${ }^{19}$

\section{A conversa com Tiradentes}

Foi numa dessas idas e vindas do alferes entre Vila Rica e o Rio de Janeiro que Salvador o conheceu. Ao ser denunciado como participante dos conciliábulos para a sublevação que se preparava em Minas, Salvador disse, durante a inquirição na cadeia de Vila Rica, que ignorava por completo a causa de sua detenção. "Não delinqüi em coisa alguma", respondeu ao ouvidor-geral Pedro José Araújo de Saldanha, corregedor da comarca, ${ }^{20}$ substituto de Gonzaga.

Negou, até mesmo, que tivesse "maior amizade" com o alferes. Admitiu, porém, que, ao precisar de um dicionário de francês, soube que o militar dispunha de um. Foi, então, procurá-lo em sua casa, que ficava na Rua de São José, próxima ao Chafariz do Largo e à mansão do ex-arrematante João Rodrigues de Macedo, conhecida como Casa do Real Contrato. Era o dia 23 de fevereiro de 1789. Estava disposto a comprar o dicionário, mas o alferes adiantou-lhe que já o havia vendido a seu irmão.

Para não decepcionar Salvador, Tiradentes disse que, antes de passar o dicionário ao seu novo dono, poderia emprestá-lo por quinze dias. Foi o que ficou acertado, segundo Salvador, que devolveu o livro no dia 7 ou 8 de março, não lembrava bem. $\mathrm{Na}$ verdade, Tiradentes não havia vendido o dicionário ao irmão, mas sim ao padre Francisco Ferreira da Cunha, seu sócio numa botica no Largo do Rosário.

Depois disso, Tiradentes, sabendo que Salvador viera do Rio de Janeiro, perguntou-lhe se não conhecia "alguns sujeitos capazes para uma empresa de empenho". Salvador, segundo declarou, disse que não dispunha de "amizades maiores" naquela cidade. "E muito menos para o fim que tu dizes", acrescentou.

Mesmo assim, o alferes insistiu, dizendo a Salvador que, se quisesse escrever para alguém no Rio de Janeiro, poderia fazê-lo para aproveitar a sua viagem. "Vou lá acertar algumas dependências com o vice-rei (Luís de Vasconcelos e Sousa) e ver também se consigo dar volta a esta história da derrama", disse o alferes, segundo o depoimento do Salvador.

\section{A derrama, o estopim}

A derrama era o assunto que preocupava a maioria das pessoas abastadas da capitania, que sempre viram com bons olhos uma revolta contra o Reino. ${ }^{21}$ Era imensa a dívida que a população mantinha com o Reino desde 1772, data da última derrama aplicada na capitania. Desde então, os débitos acumulavam-se, 
especialmente, na cobrança do quinto do ouro: com a decadência das minas, o furto e o contrabando praticados pelos poderosos, governantes, oficiais e delinquentes comuns, além da sonegação generalizada, o confisco necessário para regularizar a cobrança dos atrasados chegava, em 1786, a 384 arrobas, ou seja, 5,76 toneladas, o equivalente a toda a produção de um exercício, ficando os moradores ainda devendo 44 arrobas à Coroa. ${ }^{22}$

O secretário de Estado dos Negócios da Marinha e Ultramar, Martinho de Melo e Castro, em Lisboa, dava mostras de impaciência com a inadimplência da colônia. E decidira mandar um novo governador e capitão-general, o visconde de Barbacena, com ordens expressas para aplicar a derrama, um tributo que atingiria todos os moradores, sem levar em conta se participavam ou não da atividade mineradora. Por tudo isso, o alferes sabia que a derrama era o estopim que poderia fazer explodir a insatisfação na colônia.

A Salvador, Tiradentes emprestou não só o dicionário, mas também uma Coleção das leis constitutivas das colônias inglesas confederadas sob a denominação de Estados Unidos da América Setentrional, ${ }^{23}$ tradução francesa de 1778. Esse era o sistema de propaganda silenciosa do alferes: esperava que, com a leitura do livro, as pessoas aderissem ao seu ideal revolucionário. Ao deterem Salvador em Vila Rica, as autoridades encontrariam entre os seus pertences a subversiva coletânea. ${ }^{24}$

Depois da conversa com o alferes, Salvador disse que retornou à casa do doutor Antônio José Soares de Castro, onde residia à época. Contou ao senhorio a conversa que tivera com Tiradentes. O doutor riu: "Talvez seja alguma empresa em que o alferes está metido, de levar à cidade do Rio de Janeiro águas do rio Comprido para levantar moinhos dentro da mesma cidade", especulou.

Ao ouvidor Saldanha, Salvador recordou que, já morando em outra casa e estando enfermo, recebeu a visita de seu antigo senhorio, o doutor Antônio José Soares de Castro. ${ }^{25} \mathrm{~A}$ visita deu-se dois dias depois da prisão do antigo ouvidor, Tomás Antônio Gonzaga, que ocorreu no sábado de 23 de maio de 1789, recordou.

Naquele dia, uma segunda-feira, Salvador soube pela boca do doutor Castro que o alferes havia sido detido no Rio de Janeiro por um caso de inconfidência. "Foi, então, que refleti ser este o empenho que o dito alferes tinha para me perguntar se conhecia no Rio de Janeiro sujeitos capazes", alegou Salvador. ${ }^{26}$

\section{Auxílio ao alferes}

Acusado pelo ouvidor de prestar auxílio ao alferes, Salvador admitiu que falara a Tiradentes do coronel José da Silva Santos, que morava no Rio de Janeiro, a quem conhecia "tão somente de vista". Foi, então, contou Salvador, que o alferes se abriu com ele, dizendo que estava disposto a promover um levante: "Já tenho esta capitania e a de São Paulo na mão", disse-lhe. "Vários regimentos vão se levantar, ministros serão presos, pois querem uma testa coroada em Minas", acrescentou. 
Salvador confessou que acabou por contar esses detalhes ao doutor Castro, que lhe recomendou cautela, dizendo que "semelhantes pensamentos só podiam vir à cabeça de um doido ou bêbado". Ao revelar ao ouvidor a conversa que tivera com Tiradentes, Salvador admitiu que estavam presentes Raimundo Correia Lobo, sargento-mor dos pardos do Serro do Frio, e Crispiniano da Luz Soares, também pardo.

O ouvidor disse a Salvador que recebera informações de que, certa noite, na ponte do Ouro Preto, à porta da ferraria de Eusébio da Costa Ataíde, ele tivera uma conversa com Crispiniano da Luz Soares. Salvador admitiu a conversa, mas não recordava o assunto. "Só me lembro de ter tocado em semelhante matéria do levante na casa do doutor Antônio José", respondeu.

\section{A acareação}

Responsável pela devassa mandada abrir pelo visconde de Barbacena, o ouvidor-geral Saldanha mandou chamar Crispiniano para uma acareação. Crispiniano, de pronto, desmentiu o amigo, dizendo que nunca ouvira Salvador falar em "semelhante coisa" na casa do doutor Castro. Mas sim, certa noite, no começo de abril, pouco antes da Semana Santa, à porta da ferraria de Eusébio da Costa Ataíde.

Segundo Crispiniano, Salvador teria dito que, como estava para ocorrer uma derrama, haveria um levante. "Para este fim, já foram escritas cartas para São Paulo", teria dito Salvador. Ao que Crispiniano questionou: "Para que este procedimento, se não é novo pagar-se a derrama?". E Salvador teria respondido: "A seu tempo, você saberá". ${ }^{27}$

O ministro valeu-se do depoimento de Crispiniano para tentar convencer Salvador a falar "mais particularmente dos procedimentos do alferes". Estava claro que o praticante de cirurgia sabia mais do que confessara. Mas Salvador manteve-se na negativa. Disse que conversara com Crispiniano na casa do doutor Castro. Não recordava de lhe ter falado sobre esses assuntos quando estiveram sentados junto à ponte do Ouro Preto. ${ }^{28}$

Crispiniano não voltou atrás. Recordou até que Salvador, logo depois de pronunciar aquela última frase, levantara-se e fora atrás de uma mulher ladeira acima. Salvador reconheceu que assim agira, mas garantiu que não se recordava de que tivesse dito aquela frase. Se havia falado com Crispiniano, disse, fora para repetir o que o doutor Castro recomendara: "Que não se devia falar em semelhante coisa porque, falando-se e não se provando, incorria-se na mesma pena". ${ }^{29}$

Crispiniano comprometeu ainda mais Salvador, ao dizer ao ministro que, depois daquela conversa junto à ponte do Ouro Preto, o amigo lhe mostrara algumas cartas. "Umas são para o Rio e outras para as partes de São Paulo", disse Salvador, segundo Crispiniano, acrescentando: "São cartas de muita importância".

\section{Cartas para Parati}

Salvador admitiu que mostrara cartas a Crispiniano, mas esclareceu que 
eram destinadas uma para o seu padrinho, outra para sua madrinha e mais uma para Cláudio Rangel, moradores na vila de Parati. Com aquelas cartas, reconheceu, seguia mais uma. Era dirigida ao tenente José Alves de Azevedo, morador no Rio de Janeiro.

Com aquelas correspondências, segundo Salvador, seguia também um atestado do sargento-mor José de Vasconcelos Parada e Sousa, o Padela das Cartas Chilenas, agora já afastado do comando do quartel da Demarcação Diamantina. Com o atestado, Salvador pretendia despertar a comiseração dos padrinhos para que lhe prestassem "algumas assistências". ${ }^{30}$ Os "padrinhos" seriam, na verdade, os pais de Salvador, moradores em Parati. Às autoridades, talvez para evitar complicações à família, garantira que era filho de "pais incógnitos". ${ }^{31}$

Em seguida, o ouvidor mandou chamar o sargento-mor Raimundo Correia Lobo, que também estivera presente à conversa na casa do doutor Castro. Lobo disse que Salvador e o doutor Castro haviam tido uma "conversa em particular". De longe, porém, ele percebera que falavam do alferes Tiradentes e "de que estava para haver um levante em Minas e que se queria fazer um parlamento".

Segundo Lobo, de o doutor Castro pedira para que "não se falasse mais em semelhante matéria porque quem quer que fosse a cabeça se lhe havia de cortar". Logo disse também que Salvador lhe mostrara umas cartas que dirigia aos seus "padrinhos" na vila de Parati.

Depois, foi a vez de o doutor Castro participar da acareação. Confirmou que Salvador, certa vez, em sua morada, revelara que o alferes Tiradentes andava a tratar de uma sublevação em Minas e que, para esse fim, ia ao Rio de Janeiro. Garantiu que instara Salvador a denunciar o alferes às autoridades. E admitiu que Lobo e Crispiniano haviam estado presentes nessa ocasião.

\section{A visita do doutor Castro}

Perguntado pelo ouvidor, o doutor Castro admitiu que, depois da notícia da prisão do alferes Tiradentes e do coronel dos auxiliares Joaquim Silvério dos Reis no Rio de Janeiro, fizera uma visita a Salvador que, nessa época, já não era seu inquilino. Teria sido uma visita de cortesia porque Salvador estaria enfermo. Nessa ocasião, Salvador teria dito a Castro, referindo-se a Tiradentes: "Veja lá se lhe tenho dado a carta que ele me pedia para Francisco Manuel, em que estado eu ficava?".

Pressionado, Salvador reconheceu que o alferes lhe havia pedido uma carta de apresentação a Francisco Manuel de Melo, tenente do regimento de artilharia do Rio de Janeiro. Mas assegurou que não lhe dera a carta. E invocou o próprio testemunho do doutor Castro. ${ }^{32}$

O ouvidor, então, quis saber do doutor Castro se ele tinha conhecimento de que Salvador escrevera outras cartas para o Rio de Janeiro e São Paulo. Mas Castro só repetiu que sabia das cartas que Salvador pretendia mandar para seus "padrinhos" na vila de Parati. Castro diria ainda aos inquisidores que, por inter- 
médio de Salvador, ficara sabendo que Tiradentes pretendia ir ao Rio de Janeiro com o objetivo de "aliciar gente". ${ }^{33}$

As autoridades ficaram convencidas de que Salvador soubera que Tiradentes tramava uma sublevação, mas não o denunciou. Concluíram também que Salvador prometera dar ao alferes algumas cartas dirigidas a determinadas pessoas que lhe poderiam ajudar na sublevação. Havia, portanto, ajudado o réu Tiradentes.

\section{Condenado à forca}

Em 24 de dezembro de 1790, da nau Golfinho desembarcaram no Rio de Janeiro os membros da Alçada, que era como se designava o tribunal de inquérito visitador, um recurso comum em casos de sedição. À vista dos depoimentos, a Alçada concluiu que Salvador soubera que o alferes pretendia ir ao Rio de Janeiro “induzir e convidar gente" para a rebelião e não o denunciara às autoridades. E, ainda que não tivesse fornecido as cartas que Tiradentes pedira, como constava do processo, era certo que "prometera ajuda para o levante, e que nenhum tempo o negara".

A sua defesa, provavelmente, foi escrita pelo ex-ouvidor de Vila Rica, Tomás Antônio Gonzaga, também acusado de sedição. É o que indica a coincidência de estilo, argumentação e fecho das peças jurídicas escritas a seu favor e do coronel José Aires Gomes e do guarda-livros Vicente Vieira da Mota, ex-caixa de João Rodrigues de Macedo, antigo arrematante dos contratos de entradas e dízimos, bem como a do próprio Gonzaga.

Na noite de 17 de abril de 1792, no Rio de Janeiro, os acusados de conspirar contra a Corte foram todos levados dos diversos locais em que estavam para a cadeia pública. Foram divididos em quatro grupos e conduzidos sob escolta armada de baioneta calada. No dia seguinte, às oito horas da manhã, a Alçada, reunida extraordinariamente sob a presidência do novo vice-rei, o conde de Resende, lavrou a sentença. Uma sentença que estava pronta desde o dia 11 de março. ${ }^{34}$

Salvador Carvalho do Amaral Gurgel foi condenado à forca. Igual sentença havia sido proferida contra o alferes Tiradentes, o tenente-coronel Francisco de Paula Freire de Andrada, José Álvares Maciel, Inácio José de Alvarenga, Domingos de Abreu Vieira, Luís Vaz de Toledo Piza, José de Resende Costa, pai e filho, e Domingos Vidal Barbosa. Todos eram acusados de alta traição.

Ao antigo ouvidor Tomás Antônio Gonzaga e outros acusados, como Vicente Vieira da Mota, José Aires Gomes, João da Costa Rodrigues, Antônio de Oliveira Lopes e Vitoriano Gonçalves Veloso, coubera pena menor: degredo em várias localidades da África.

\section{Degredo na África}

Dezoito meses antes de lavrada a sentença, a rainha dona Maria I, por carta régia de 15 de outubro de 1790, sem que ninguém soubesse, comutara a pena 
de morte em degredo perpétuo na África, fazendo exceção para réus reputados por "chefes e cabeças da conspiração", que procurassem em público, como em particular, induzir os povos a atos criminosos.

A exceção incluía apenas o alferes Tiradentes, que fora, afinal, "o primeiro motor da projetada sublevação, o que mostrava maior empenho e eficácia na execução dela". ${ }^{35}$ Os outros condenados à forca tiveram assim a pena alterada para degredo nas conquistas portuguesas na África. Já os religiosos implicados na trama subversiva iriam para Lisboa.

Os réus não condenados à pena máxima foram intimados a 24 de abril. No dia seguinte, José de Oliveira Fagundes, advogado dativo da Santa Casa de Misericórdia, retirou os autos com 24 horas de prazo para embargar a sentença. O embargo, porém, foi rejeitado. E Salvador Carvalho do Amaral Gurgel acabou condenado a degredo para toda a vida em Catalá.

Antes de seguir viagem para o degredo, no dia 16 de maio, Salvador encaminhou documento às autoridades em que pedia que lhe restituíssem um estojo de cirurgia, com cinco lancetas e ferros, que havia sido apreendido por ocasião de sua prisão. E lembrou que, como ia "para uma terra estranha", poderia precisar do estojo "para socorro de sua sustentação". ${ }^{36}$ Dos bens sequestrados, que haviam ficado de posse de um depositário, constava também um "livro das Estações de Jerusalém". ${ }^{37}$

No dia 22 de maio, terça-feira, Salvador embarcava, em companhia de Tomás Antônio Gonzaga, José Aires Gomes, Vicente Vieira da Mota, Vitoriano Gonçalves Veloso, João da Costa Rodrigues e Antônio de Oliveira Lopes, na galera Nossa Senhora da Conceição e Princesa de Portugal, com destino à ilha de Moçambique. Talvez à espera de ventos mais favoráveis, a nau só zarparia na sexta-feira, dia 25. Salvador, um dos mais jovens entre os inconfidentes, ia cumprir o seu degredo na África.

\section{A ilha de Moçambique}

O capitão Francisco Bernardes de Abreu e Lima, comandante da galera, dispensou bom tratamento a todos os condenados. ${ }^{38}$ Foi uma viagem de setenta dias. E, em 31 de julho, uma terça-feira, do tombadilho da galera, em companhia dos demais degredados, Salvador viu a vila de São Sebastião, nome da ilha-capital da capitania de Moçambique, Rios de Sena e Sofala, as conquistas portuguesas da África Oriental.

A ilha é uma espécie de meia-lua, cujo côncavo está voltado para o Sul. É baixa e quase plana, com seu terreno calcário coberto de areia. Da galera, Salvador avistou uma pequena povoação quase no meio da ilha, onde se destacavam dois edifícios: o palácio do governo e a alfândega, por cima da muralha de pedra de uma vasta praça.

No outro lado, nas Terras Firmes, viu edifícios menores - lá era a Cabaceira Grande, viria a saber. Mais para adiante, estava o Mossuril, também no continente. E, no outro lado, a Cabaceira Pequena. No cais, observou apenas 
pangaios, escunas e sumacas - como o porto era pouco profundo e repleto de coroas de areia, só pequenas embarcações podiam chegar à praia. As maiores ficavam ao largo, a mais de 200 metros, próximas a um cais de pedra que avançava pelo mar.

O lugar de desembarque ficava do ancoradouro um tiro de espingarda. E era bastante incômodo não só para o embarque e desembarque de gente como de cargas. Salvador e os demais degredados desembarcaram em pequenos escaleres. Depois, subiram por escadinhas de pedra até um velho cais construído sobre colunas.

Os degredados foram recebidos em terra "com honra". ${ }^{39}$ E levados imediatamente ao Palácio de São Paulo, a sede do governo, onde despachava e vivia o governador e capitão-general Antônio Manuel de Melo e Castro, sobrinho do todo-poderoso ministro Martinho de Melo e Castro. Foram recebidos pelo secretário do governo, o naturalista Manuel Galvão da Silva, um baiano de quarenta e poucos anos, formado em Matemáticas, Filosofia e Leis por Coimbra.

\section{Vidas em reconstrução}

Ao lado dos companheiros de infortúnio, Salvador ouviu Galvão avisar que poderiam reconstruir a vida, desde que não ofendessem as regras régias. Não poderiam retornar ao Estado do Brasil nem viajar para o Reino sob o risco de serem condenados à morte. Da ilha também não poderiam sair sem passaporte do governo, mas essa norma valia para todos os habitantes.

O governador mostrou-se simpático com os degredados. Disse-lhes que poderiam circular livremente pela ilha, desde que não avançassem além do Tanque dos Mainatos, lugar privativo dos negros gentios e vedado a brancos que lá não fossem em grupos armados ${ }^{40} \mathrm{~A}$ recomendação valia também para quem sonhasse explorar os sertões, nas Terras Firmes, onde viviam os macuas, os macondes, os mavias e os mujaos, tidos como ferozes e de bárbaros costumes.

Entusiasmados com a boa recepção, os condenados a viver em outras localidades da África Oriental, como Salvador, passaram a sonhar com a possibilidade de requerer a ilha de Moçambique por menagem, permanecendo na vila. Do Palácio de São Paulo, os degredados foram levados à Casa da Câmara e Cadeia, onde ficariam hospedados "com toda a liberdade e estimação em salas da Câmara". ${ }^{41}$

Logo receberiam a visita das principais pessoas da terra, não só reinóis, como banianes, que eram os comerciantes muçulmanos, súditos da Coroa, procedentes de Diu e Damão. Foram procurados até por monhés, os macuas muçulmanos, sempre vestidos de branco, maganjas e suakikis, negros exóticos oriundos de outras regiões, todos já acostumados ao grosso comércio.

Só o antigo ministro Tomás Antônio Gonzaga não ficou na Casa da Câmara: a convite do desembargador José da Costa Dias e Barros, hospedara-se na Casa do Ouvidor, uma imponente construção próxima ao palácio do governo. 


\section{Falsos testemunhos}

Bastante doente, o ouvidor-geral Barros, impaciente com a demora do substituto, decidiu largar a vara e, com a aprovação do governador, embarcou na galera Nossa Senhora da Conceição e Princesa de Portugal, que, em 26 de agosto, deixou a ilha de Moçambique com destino a Goa, na Índia portuguesa, de volta ao Reino. Quatro dias depois, a bordo de outra nau, chegava o novo ouvidor, Francisco Antônio Tavares de Siqueira, que logo haveria de nomear Gonzaga promotor de defuntos e ausentes e advogado dos auditórios públicos.

Para tirar o processo de residência do ouvidor que deixara a vara, Siqueira, como era de praxe, teve de ouvir várias testemunhas. Recorreu a Gonzaga que, à falta de pessoas dispostas a testemunhar em favor de Barros, convenceu seus amigos degredados a colaborar. E lá foi Salvador, com os companheiros de exílio, depor na sindicância em favor de Barros.

Foi uma sindicância de cartas marcadas. Afinal, os degredados mal tinham conhecido o antigo ouvidor, até mesmo em razão do pouco tempo que conviveram na terra. ${ }^{42}$ Talvez os inconfidentes tenham imaginado que, colaborando com as autoridades, poderiam continuar na ilha de Moçambique, em vez de serem mandados para os locais de seu degredo.

Não foi só dessa vez que o antigo ministro Gonzaga, agora nas boas graças do novo ouvidor, tratou de utilizar a boa vontade dos companheiros de degredo. Talvez o próprio Gonzaga pensasse que, assim, poderia ajudá-los a continuar na capital. Tanto que, meses mais tarde, voltou a recorrer a igual expediente.

Foi num caso que envolvia Manuel do Nascimento Nunes, advogado que viera degredado do Reino por crime que cometera no Alentejo. Incumbido de dar sequência a um processo contra Nunes que rolava na Justiça de Moçambique havia seis anos, Gonzaga recorreu aos seus amigos. E, outra vez, lá foi Salvador, ao lado dos outros cinco inconfidentes, depor contra Nunes, a quem também mal conhecia. ${ }^{43}$

\section{Ajudante de cirurgião-mor}

Apoiado pelas boas relações do antigo ouvidor de Vila Rica, Salvador aproveitou para tentar refazer a vida na ilha de Moçambique. Como o governador Melo e Castro não colocava obstáculos a que todos os degredados permanecessem na ilha, Salvador tratou de arrumar emprego em que pudesse exercitar a arte de cirurgião. E, em setembro, acabou por sentar praça como ajudante de cirurgião-mor do regimento de infantaria. ${ }^{44}$

Passou a trabalhar sob a ordens do físico-mor João Domingos Tosco, nome aportuguesado de Giovanni Domenico Thosco, médico piemontês formado em Turim e admitido ao real serviço português. Mas foi por pouco tempo porque Tosco, inebriado pelos lucros fáceis do comércio, largaria seus instrumentos e compraria um navio para buscar carregação de ouro e marfim. Não teve sorte porque morreria, em 1794, num naufrágio, próximo ao estabelecimento francês de Pont Chery, no Índico. ${ }^{45}$ 
Antes de partir, porém, Tosco assinou, em 20 de março de 1793, um elogioso atestado da capacidade de Salvador. ${ }^{46}$ No atestado, garantiu que Salvador tinha "servido no Hospital Real como nas casas particulares dos habitantes desta capatinia com muitas capacidade". E assegurou que Salvador o substituíra, muitas vezes, nas visitas aos doentes.

"Sempre achei nele suficiente inteligência e acerto nos diagnósticos e curativos das enfermidades médicas", acrescentou. No lugar de Tosco, ficaria outro médico piemontês, Charles Joseph Guezzi, ou Carlos José Guezzi, que logo também haveria de largar os instrumentos cirúrgicos para se transformar em grande traficante negreiro e, mais tarde, "agente confidencial" do príncipe regente dom João em Buenos Aires. ${ }^{47}$

\section{Degredo em Inhambane}

A vida que para Salvador parecia agora seguir um curso normal logo seria abalada com a chegada do novo governador e capitão-general, dom Diogo de Sousa Coutinho, que substituiria Antônio Manuel de Melo e Castro em março de 1793.

Dom Diogo, ao contrário de Melo e Castro, era pouco afável. Talvez porque não só sofria de escorbuto e lepra e ficara sem os dentes, ${ }^{48}$ como também tivera a má sorte de perder logo nos primeiros dias a mulher Ana Cândida, ${ }^{49}$ vítima de uma das muitas doenças que os monomocaios ${ }^{50}$ traziam para a ilha, segundo a crença dos moradores.

Dom Diogo entendeu que os degredados que haviam sido condenados para outras localidades da África Oriental não poderiam mais permanecer na ilha-capital. Embora se tivesse tornado amigo de Gonzaga, a Salvador, agora, de nada valeria a amizade: para dom Diogo, o antigo ouvidor de Vila Rica não passava de um "advogado bastantemente venal e sumamente embrulhador e intrigante" ${ }^{51}$ De nada adiantaria falar com os grandes comerciantes de escravos, as pessoas mais influentes da ilha, porque ninguém tiraria da cabeça de dom Diogo aquela ideia.

Assim, em 29 de novembro de 1793, Salvador foi mandado servir no destacamento do porto de Inhambane, ao Sul da capitania. Livrara-se de Catalá, como a condenação mandava, mas, à época, pouca diferença podia haver entre aquela localidade e Inhambane.

Iria em companhia do coronel José Aires Gomes, outro inconfidente, antigo fazendeiro da Borda do Campo e ex-fiador do contrato dos dízimos arrematado pelo rendeiro João Rodrigues de Macedo em Minas pelo período de 1777 a 1783. Por ordem de dom Diogo, o governador de Inhambane garantiria a Salvador mantimentos por dois meses. ${ }^{52}$

\section{A vida em Inhambane}

A vila era, àquela altura, uma incipiente povoação com pouco mais de cinquenta casais. Eram poucos os brancos e os pardos - a maioria era de escu- 
ros naturais do país. ${ }^{53}$ Havia também muitos escuros procedentes de Goa, os chamados canarins. Quase todos tinham macuas, aos quais chamavam genericamente de cafres, como escravos. A vida girava em torno do presídio, nome que, no século XVIII, queria designar apenas o destacamento, que incluía uma pequena cadeia.

Salvador, rapidamente, teve de se adaptar aos costumes locais. Praticou a medicina, mas também se dedicou ao comércio. Estava entre iguais. Eram aqueles homens quase todos degredados. E pessoas de escassas letras. Por isso, logo Salvador ganhou um cargo de vereador no Senado da Câmara. Foi em 1794, poucos meses depois de sua chegada. Continuou a exercer o cargo em 1795, confirmado que fora pelo ouvidor-geral da capitania, Tavares de Siqueira, em 31 de outubro de $1794 .^{54}$

\section{A morte de Aires Gomes}

Logo, Salvador perderia a companhia do coronel Aires Gomes. De constituição debilitada e idade já avançada para a época, Aires Gomes não resistiria ao clima inóspito de Inhambane. E morreria em 1796. Tinha, então, 62 anos. A princípio, havia sido condenado a "degredo para toda a vida" em Ambaca, Angola, na África Ocidental, mas, depois, a Alçada modificara a pena para oito anos em Inhambane.

Extremamente rico, Aires Gomes tivera confiscada pelas autoridades régias metade de seus bens, mas ainda assim era proprietário de terras tão extensas que causariam inveja a qualquer monarca europeu. Em Minas, deixara mulher, dona Maria Inácio de Oliveira, e os filhos João Ribeiro, João Aires e José Aires Gomes, além das filhas Ana Pérpétua e Maria Antônia. ${ }^{55}$

Os poucos anos de convivência diária com Aires Gomes serviriam, no entanto, para Salvador selar uma grande amizade com o antigo fazendeiro. Ao casar com dona Amanda Guiães, Salvador, quando ganhou um filho, fez questão de batizá-lo com o nome de Aires em homenagem ao amigo. ${ }^{56}$

\section{Presidente do Senado da Câmara}

Como cirurgião do destacamento, Salvador não recebia soldo em dinheiro, mas em fato, que era o nome que designava os panos que os soldados recebiam como pagamento. Para fazer dinheiro metálico ou obter as valorizadas patacas espanholas, tinham de negociar esses panos com os cafres ou régulos do sertão. O regimento do destacamento era tão pobre que os soldados quase sempre andavam descalços e sem farda. Como era uma tropa insignificante, não havia sequer a tradicional divisão entre artilharia e infantaria.

Salvador voltaria a desempenhar a função de vereador de 1801 a 1802. "Não há impedimento e é merecedor", elogiou-o o ouvidor da época, José Félix Potier Lamas, ao confirmá-lo para o cargo de 1802. Em 1803, tornou-se presidente do Senado da Câmara e, no ano seguinte, serviu como almotacé durante o primeiro trimestre, como obrigava a lei a quem exercera o mais alto posto da 
Câmara. ${ }^{57}$ Almotacé era o nome que se dava para o inspetor encarregado da aplicação dos pesos e das medidas e da taxação dos gêneros alimentícios.

\section{Cuidando da pobreza}

No porto de Inhambane, como cirurgião do destacamento, Salvador não só tratou da tropa, como dos enfermos da cadeia e dos moradores. "Até chegou a manobrar remédios por sua própria mão para suprir a falta de farmacêutico", garantiu o governador Joaquim José Felipe Caminha, ao escrever um atestado que leva a data de 12 de julho de $1805 .^{58}$

A falta de remédios sempre preocupou as autoridades da vila, já que ficavam na dependência do envio de medicamentos por parte do governo da ilha de Moçambique, que os recebia do Reino ou, mais frequentemente, os comprava na Ilha de França, capital das possessões francesas no Índico. ${ }^{59}$

De acordo com o testemunho de Caminha, Salvador tratava da tropa "com excessivo cuidado e igualmente a todos os moradores", não faltando quando foi chamado por qualquer enfermo. "Ele à pobreza curava com muita humanidade e até os remédios lhe dava gratuitamente de sua própria botica", disse. "Salvador sempre se comportou com muita gravidade e civilidade, não encontrando no tempo de meu governo queixa dele alguma tanto em falta de seu cargo como no trato civil", acrescentou Caminha.

Também o alcaide-mor da ilha de Moçambique, Antônio Alberto Pereira, que havia sido governador e capitão-mor da vila de Inhambane durante três anos, atestou que Salvador "sempre se conduziu com zelo e prontidão no curativo da tropa e dos habitantes, fazendo propriamente os medicamentos, sem ser essa a sua obrigação".

Segundo Pereira, o antigo inconfidente tratava das enfermidades das pessoas "com exemplar caridade, isto muitas vezes em prejuízo pessoal". Até mesmo doente, Salvador fazia questão de atender quem o procurava, afirmou Pereira.

Sobre o comportamento pessoal de Salvador, Pereira disse que sempre o achara "livre de nota, cheio de gravidade, sem vício algum que denegrisse a sua honra". Pereira garantiu que tudo aquilo era tão verdade que, se preciso, o juraria aos Santos Evangelhos. É o que consta de um atestado que escreveu em 2 de outubro de $1806 .{ }^{60}$

\section{$\mathrm{O}$ retorno à ilha}

Salvador viveria em Inhambane onze anos e alguns meses. Ao final de 1804, autorizado pelo governador e capitão-general Isidro de Almeida e Sá, retornou à ilha de Moçambique. Era o dia 5 de novembro, quando desembarcou de um brigue. Chegava para exercer o ofício de ajudante de cirurgião-mor, ${ }^{61}$ como fizera mais de uma década antes. Para o seu lugar em Inhambane, foi despachado Antônio Manuel Luís.

Retornara à ilha, provavelmente, por influência de Tomás Antônio Gonzaga, que, por esse tempo, gozava de boas relações com o governador Isidro 
Sá. Mas chegava só e com a saúde arruinada. ${ }^{62}$ Por andar doente, pedira ao governador e capitão-mor da vila de Inhambane, José Joaquim Felipe Caminha, demissão do cargo de cirurgião do destacamento local.

Sua saúde fora abalada pelo clima seco de Inhambane. Em 1804, por exemplo, uma grande seca destruíra plantas e flores, afetando, principalmente, as plantações de cebolas de Inhambane. ${ }^{63}$ Salvador deixaria em Inhambane "ao desamparo sua casa, mulher e um filho". ${ }^{64}$

\section{Um santo}

O antigo inconfidente recuperaria em parte a boa disposição e, em 8 de agosto de 1806, seria nomeado interinamente cirurgião-mor do Estado, no lugar de Francisco Pires de Carvalho, que iria cuidar de sua própria saúde na Ilha de França.

Desde março, quando Carvalho caíra de cama, Salvador já o vinha substituindo nas visitas aos doentes da enfermaria e cirurgia do Hospital Real da Ilha de Moçambique. ${ }^{65}$ Ao nomeá-lo, o novo governador e capitão-general Francisco de Paula Albuquerque do Amaral Cardoso, substituto de Isidro Sá, dele diria que tinha "dado provas de ser hábil, inteligente e de bons costumes" ${ }^{66}$

Em 12 de junho de 1807, Salvador seria, por fim, nomeado cirurgião-mor do regimento de infantaria da ilha de Moçambique. ${ }^{67}$ Tinha, à época, 45 anos de idade e "dois anos, cinco meses e 27 dias de serviço sem nota neste regimento". Durante esse tempo, na ilha de Moçambique, voltaria a desempenhar seu trabalho com uma dedicação franciscana. Era considerado santo pela população humilde da ilha - os escravos, pretos forros, que residiam no bairro da Miçanga em tembas ${ }^{68}$ cobertas por colmos.

Tanto que, a essa época, Sebastião José Rodrigues, ex-cirurgião-mor do regimento de infantaria, cavaleiro da Ordem de São Tiago e um dos cinco maiores traficantes de escravos da capitania, também faria elogios à atuação de Salvador como ajudante de cirurgião-mor: "Ele se incumbia de todo curativo no Hospital Real e sempre mostrou desempenho sem cometer erro algum", assegurou. Também o físico-mor José de Melo certificou que Salvador, durante alguns meses, servira no lugar de cirurgião-mor da capitania, satisfazendo bem "os deveres deste emprego".

Por esse tempo, Salvador assinou um atestado para o soldado Francisco Nunes, da quinta companhia do regimento de infantaria da guarnição da praça de Moçambique. Segundo o cirurgião-mor, o soldado tinha "duas chagas numa perna, as quais por sua antiguidade e lavra que tem no osso, se fazem incuráveis". ${ }^{69}$

Salvador nunca recuperaria por completo a boa forma física. Aos 48 anos de idade, num relatório do regimento de infantaria, aparece como pessoa de "boa conduta e pouca saúde". ${ }^{70}$ Mesmo assim, na ilha-capítal, pôde melhorar de vida e mandou chamar para junto de si a mulher e o filho. Ao final de 1807, já aparecia como próspero morador. 
Além do trabalho como cirurgião-mor do regimento, ${ }^{71}$ ainda encontrava tempo para ajudar os amigos. Foi o que fez em abril de 1809, quando atuou como procurador de José de Sousa Taveira, tenente e comandante do corpo de artilharia do porto de Inhambane, que reivindicava ao governo interino da capitania o posto de capitão de sua unidade..$^{72}$

\section{Proprietário de escravos}

Numa relação que especifica a escravatura nas mãos dos moradores da ilha de Moçambique, Salvador aparece como proprietário de sete escravos. Era um dos que menos possuíam escravos. O advogado Tomás Antônio Gonzaga, agora procurador da Coroa, dispunha de trinta homens. ${ }^{73}$

Os grandes traficantes negreiros aparecem como proprietários de uma, duas e até centenas de escravos. A escravaria de Salvador aparece como localizada no distrito do Mossuril, o que significa que o cirurgião-mor era proprietário de uma pequena machamba ${ }^{74}$ nas Terras Firmes. Os escravos deviam trabalhar nas plantações ou no serviço doméstico no luane. ${ }^{75}$

\section{A morte do governador}

Nos últimos dias de 1807, o governador e capitão-general Francisco de Paula, depois de afrontar os interesses de alguns comerciantes negreiros, isolouse no Palácio de São Paulo. E acabou por adoecer. Procurou, então, recuperar a saúde no palácio de verão dos governadores de capitães-generais, que ficava no Mossuril, nas Terras Firmes.

Foi ao cirurgião-mor do regimento Salvador Carvalho do Amaral Gurgel que Francisco de Paula recorreu. Provavelmente porque andava em divergências com o físico-mor José de Melo e não tivesse em boa conta o cirurgião-mor do Estado, Francisco José Pires de Carvalho.

Salvador empenhou-se como sempre. A todo momento, garantia que "a moléstia não era de perigo". ${ }^{76}$ Chamado a tratar do governador, o físico-mor José de Melo repetiu que o ilustre paciente não inspirava cuidados. Mas o governador acabou por morrer às 10 horas da manhã do dia 18 de dezembro. ${ }^{77}$

De imediato, correu pela ilha o boato de que o governador havia sido morto "cavilosamente". Até porque eram frequentes as notícias sobre a morte de autoridades por envenenamento. Alertado por esses murmúrios, o recém-empossado ouvidor Agostinho Bernardo Delgado Pinto determinou que o físico-mor José de Melo e o cirurgião Salvador fizessem o exame do cadáver. Ambos atestaram que o governador falecera "ao sétimo dia de uma moléstia que fora natural", depois de uma febre renitente e perniciosa, "aparecendo uma decidida podridão e todos os sinais de uma morte verdadeira". ${ }^{78}$

A desconfiança, porém, só haveria de persistir em relação ao físico-mor José de Melo, que fora a última pessoa a estar com o governador. Até porque Melo, anteriormente, havia se atritado com o governador por causa de interesses comerciais. Além disso, era amigo do tenente-coronel Constantino Antônio 
Alves da Silva, comandante do forte de São Lourenço, inimigo acérrimo do governador.

Para o bispo de Olba, que haveria de assumir o poder como integrante de uma junta governativa, ficara a impressão de que Melo matara Francisco de Paula ou "não lhe dera os remédios competentes e a tempo para que não morresse".$^{79}$ De Salvador, ninguém levantou qualquer dúvida. Estava acima de qualquer suspeita.

\section{O reconhecimento da Corte}

Ao final de 1809, Salvador requereu ao príncipe regente dom João o emprego de cirurgião-mor vitalício da capitania de Moçambique, em substituição a Francisco Pires de Carvalho, lembrando que tinha "a prática do país, o que não terá outro que vier da Corte". ${ }^{80}$

Pediu também a mercê do hábito da Ordem de Cristo.$^{81}$ À solicitação, o antigo inconfidente anexou vários atestados de seu bom comportamento tanto no porto de Inhambane como na ilha de Moçambique. Ao todo, dizia ter quatorze anos e quatro meses de África.

O novo governador e capitão-general Antônio Manuel de Melo e Castro de Mendonça, que substituíra o governo interino, apoiaria a primeira pretensão, atestando a boa conduta do suplicante. Quando ao hábito da Ordem de Cristo, opinou que Salvador só poderia requerê-lo "quando passasse a capitão e tivesse vinte anos de serviço sem nota". ${ }^{82}$ Mas recomendou que lhe fosse cedida uma das casas do fisco para morar e passasse a receber tanto quanto o cirurgião-mor da capitania, "já que ganha pouco". O príncipe regente determinou que fosse Salvador quem ficasse com o emprego de cirurgião-mor quando o cargo vagasse. ${ }^{83} \mathrm{E}$ atenderia prontamente à recomendação para the dar uma das casas do fisco para sua morada. ${ }^{84}$ Da Corte, Salvador nunca receberia resposta para a pretensão de ganhar o hábito da Ordem de Cristo.

\section{A morte do amigo Gonzaga}

Entre o final de janeiro e o começo de fevereiro de $1810,{ }^{85}$ Salvador perdeu o seu grande amigo Tomás Antônio Gonzaga, procurador da Real Fazenda e juiz interino da alfândega. ${ }^{86}$ Doente desde o começo de dezembro de 1809 , Gonzaga faltaria muitos dias ao serviço.

É possível imaginar que, diariamente, Salvador passasse pela casa do amigo, na Rua do Largo da Saúde, no bairro alto da Marangonha, na ponta Sul da ilha, para assisti-lo e medicá-lo. Gonzaga sofria de ressecamento dos intestinos, e, entre os remédios que requereu, no dia 15 de dezembro de 1809 , à botica do Hospital Real, estavam duas onças de flor de sabugueiro e duas onças de unguento amarelo. ${ }^{87}$ Como cirurgião-mor, era Salvador quem liberava os medicamentos para "a casa do doutor Gonzaga".

Como era costume à época, talvez receitasse ao velho amigo infusão de sabugueiro com casca de laranja. Ou algum clister laxativo. Era também hábil 
na aplicação de sanguessugas. Deve ter tido todo empenho para ver Gonzaga recuperado. Mas o esforço seria em vão. Foi o único inconfidente à beira do leito de morte do poeta.

\section{Os últimos dias}

Depois da morte do amigo Gonzaga, em 1810, Salvador requereu licença para retornar ao Brasil, mas o pedido seria negado pelo governador Mendonça sob a alegação de que sua saída seria uma grande perda para a capitania. ${ }^{8}$ Teria mesmo de se conformar e viver os seus últimos dias no exílio africano.

O inconfidente Salvador Carvalho do Amaral Gurgel morreu na ilha de Moçambique em 10 de outubro de 1812 , com cinquenta anos de idade. ${ }^{89}$ Isso significa que seus restos mortais não se encontram no Museu da Inconfidência, em Ouro Preto, ao contrário do que diz a história oficial.

Em novembro de 1936, a pedido do presidente brasileiro Getúlio Vargas, o governo português mandou recolher na África os restos mortais de todos os inconfidentes. No dia 24 de dezembro de 1936, chegava ao Rio de Janeiro o navio nacional Bagé com os ossos dos inconfidentes de 1789, sob a guarda do escritor Augusto de Lima Júnior.

Segundo Lima Júnior, Salvador teria morrido em 1805 e seu corpo fora sepultado na igreja paroquial de Nossa Senhora da Conceição de Inhambane. ${ }^{90}$ Seus restos mortais, em 1936, teriam sido exumados naquela igreja e transportados para o Museu da Inconfidência.

Mas parece que as autoridades brasileiras foram ludibriadas. Ou se deixaram enganar. O escritor Joaquim de Montezuma de Carvalho, morador na antiga Lourenço Marques, hoje Maputo, disse, com ironia, que "até terra de umas sepulturas de Inhambane chegou a ser levada para o Brasil".91

De fato, em 1971, em correspondência a Montezuma de Carvalho, Alexandre Lobato, diretor do Arquivo Histórico de Moçambique, confirmou que, em 1936, diante da dificuldade para localizar os túmulos dos inconfidentes, as autoridades coloniais não fizeram o trabalho com o rigor necessário. Foi, por exemplo, o que ocorreu com os restos mortais do poeta Gonzaga: em vez dos ossos do poeta, vieram para o Brasil os de seu neto, Tomás Antônio Gonzaga de Magalhães, falecido em 1855. ${ }^{92}$

\section{O último inconfidente na África Oriental}

Quinze dias antes da morte de Salvador, o príncipe regente dom João, com a Corte instalada no Rio de Janeiro desde 1808, assinou decreto em que o nomeava físico-mor da capitania da Moçambique, Rios de Sena e Sofala, ${ }^{93} \mathrm{em}$ substituição a José de Melo que, com “problemas de saúde e a família na miséria em Portugal", queria voltar.94

Mas, quando a nau que levava a carta de sua nomeação chegou à ilha de Moçambique, Salvador Carvalho do Amaral Gurgel já era apenas uma lembrança entre os humildes que se serviam de sua arte e de seus medicamentos. Foi o último dos inconfidentes de 1789 a morrer na África Ocidental. 
Notas

1 Daniel P. Kidder, Reminiscências de viagens e permanência no Brasil, Rio de Janeiro e província de São Paulo, citado em Tricentenário de Parati-notícias históricas, p.65.

2 José de Sousa Azevedo Pizarro e Araújo (e outros), Tricentenário de Parati-notícias históricas, p.12-3.

3 Autos da Devassa da Inconfidência Mineira (ADIM), 2.ed., v.2, 1978, nota de Tarquínio J. B. de Oliveira.

4 José de Sousa Azevedo Pizarro e Araújo, “Memórias históricas do Rio de Janeiro”, op. cit., p.31.

5 Ibidem, p.40.

6 Arquivo Histórico Ultramarino (AHU), Conselho Ultramarino, códice 1349, fl.51.

7 ADIM, 2.ed., v.2, p.216, nota de Tarquínio J. B. de Oliveira.

8 Ibidem, v.8, p.368, nota de Tarquínio J. B. de Oliveira.

9 Ibidem, v.4, p.123.

10 Tomás Antônio Gonzaga, Cartas Chilenas, Carta 10, v.96.

11 Revista do Instituto Histórico e Geográfico Brasileiro, v.8, t.8, 1881; ADIM, 2.ed., v.8, p.349, depoimento do inconfidente José Resende da Costa, filho, em 1826, depois de seu regresso ao Brasil.

12 Arquivo Público Mineiro (APM), Seção Colonial, códice 241, fl.12v., 21.4.1784.

13 Arquivo Nacional do Rio de Janeiro (ANRJ), códice 5, v.1, fl.149.

14 AHU, Minas Gerais, caixa 135, 4.9.1787.

15 APM, Secretaria do Governo, caixa 17, doc.37, mapa da tropa paga referente ao terceiro trimestre de 1787.

16 AHU, Minas Gerais, caixa 135, 19.8.1788.

17 AHU, Rio de Janeiro, Avulsos, caixa 142, doc.8, 18.8.1788. Agradeço a referência ao historiador Nireu Cavalcanti.

18 Biblioteca Nacional do Rio de Janeiro, Casa dos Contos, II, 31.31.8.

19 ADIM, 2.ed., v.1, p.165.

20 Ibidem, v.2, p.218.

21 ANRJ, códice 5, v.4, fl.176v.

22 Tarquínio J. B. de Oliveira, Cartas Chilenas - fontes textuais, p.163.

$23 \mathrm{O}$ exemplar hoje faz parte do acervo do Museu da Inconfidência, em Ouro Preto. O livro é dado como impresso na Suíça.

24 ADIM, 2.ed., v.3, p.466.

25 Ibidem, v.2, p.219.

26 Ibidem.

27 Ibidem, v.4, p.143.

28 Ibidem, p.222.

29 Ibidem, p.223. 
30 Ibidem, p.224.

31 Ibidem, p.142.

32 Ibidem, p.124.

33 Ibidem, p.123.

34 Biblioteca Nacional de Lisboa, Coleção Pombalina, miscelânea 643, fls.349-450.

35 ADIM, 2.ed., v.8, p.192-3.

36 Ibidem, v.6, p.486.

37 Ibidem, v.3, p.447.

38 Ibidem, v.9, p.207, carta de Vicente Vieira da Mota a João Rodrigues de Macedo.

39 Ibidem.

40 Alexandre Lobato, A ilha de Moçambique, p.37.

41 ADIM, 2.ed., v.9, p.207, carta de Vicente Vieira da Mota a João Rodrigues de Macedo.

42 AHU, Moçambique, caixa 75, doc.66, 29.7.1796, denúncia do escrivão Apolinário José Luís.

43 AHU, Moçambique, caixa 75, doc.66, 29.9.1796.

44 AHU, Moçambique, códice 1349, fl.51, 7.9.1792.

45 AHU, Moçambique, caixa 213, doc.67, 29.11.1828.

46 AHU, Moçambique, caixa 134, 61-A, 6.11.1810.

47 Oliveira Lima, D. João VI no Brasil, 2006, p.233

48 AHU, Moçambique, caixa 68, doc.69, 25.8.1794.

49 Santana Sebastião da Cunha, padre, Antiguidades históricas da Ilha de Moçambique e do litoral fronteiro, desde os tempos da ocupação, p.191.

50 Monomocaios: tufões.

51 AHU, Moçambique, caixa 72, doc.58, post. a nov. 1795.

52 AHU, Moçambique, caixa 1360, fl.105, 2.11.1793.

53 Biblioteca Pública Municipal do Porto, códice 588, "Descrição da capitania de Moçambique com a informação e algumas observações sobre o estado em que, nos fins do ano de 1789, ficavam os negócios, a população, o comércio, os presídios, a administração da justiça de cada uma das vilas desta capitania e algumas outras observações particulares", por Jerônimo Nogueira de Andrade, capitão da artilharia agregado à primeira plana da corte.

54 AHU, Moçambique, caixa 134, doc.61-A, 26.11.1810.

55 José Bonifácio, “A Fazenda Borda do Campo: o inconfidente José Aires Gomes”, Revista do Arquivo Público Mineiro, ano 11, p.636, 1906-1907.

56 ADIM, 2.ed., v.2, p.216, nota de Tarquínio J. B. de Oliveira.

57 Ibidem.

58 AHU, Moçambique, caixa 134, doc.61-A, 26.11.1810.

59 AHU, Moçambique, caixa 75, doc.22, 14.9.1796.

60 AHU, Moçambique, caixa 134, doc.61-A, 26.11.1810.

61 AHU, Moçambique, caixa 134, doc.61-A, 26.11.1810. 
62 AHU, Moçambique, códice 1349, fl.100, c.1804.

63 AHU, Moçambique, caixa 105, doc.60, 20.2.1804.

64 AHU, Moçambique, caixa 134, doc. 61-A, 26.11.1810.

65 AHU, Moçambique, caixa 134, doc.61-A, 26.11.1810.

66 AHU, Moçambique, códice 1347, fl. 90, 8.8.1806.

67 AHU, Moçambique, caixa 134, doc.61-A, 26.11.1810.

68 Tembas: palhoças ou choças.

69 AHU, Moçambique, caixa 120, doc.122, 18.6.1807.

70 AHU, Moçambique, caixa 140, doc.18, 24.9.1812.

71 AHU, Moçambique, caixa 122, doc.53-A, 17.2.1808.

72 AHU, Moçambique, caixa 126, doc.71-A, 17.4.1809.

73 AHU, Moçambique, caixa 121, doc.98, 23.12.1807.

74 Machamba: plantação de mandioca.

75 Luane: casa senhorial numa propriedade agrícola.

76 AHU, Moçambique, caixa 122, doc.2, 16.1.1808.

77 AHU, Moçambique, caixa 122, doc.2, 16.1.1808.

78 AHU, Moçambique, caixa 122, doc.2, 16.11.1808.

79 AHU, Moçambique, caixa 134, doc.2, 15.1.1808.

80 AHU, Moçambique, caixa 134, doc.61-A, 26.11.1810.

81 AHU, Moçambique, caixa 130, doc.29, 6.12.1809.

82 AHU, Moçambique, caixa 130, doc.29, 6.12.1809.

83 AHU, Conselho Ultramarino, códice 538, fls.21v./22, 6.4.1810.

84 AHU, Moçambique, códice 1375, fl.18, 18.4.1810.

85 AHU, Moçambique, códice 1377, f.18, 24.1.1810. Último ofício do governador ao juiz interino da alfândega Tomás Antônio Gonzaga.

86 AHU, Moçambique, códice 1378, fls.51-51v., 2.2.1810. Posse de Antônio da Cruz e Almeida no cargo de procurador da Real Fazenda que se achava "vago por falecimento de Tomás Antônio Gonzaga".

87 Arquivo Histórico de Moçambique, códice 11-4483, fl.90v., 15.12.1809. Agradeço ao professor Gerhard Liesegang, do Departamento de História da Universidade Eduardo Mondlane, de Maputo.

88 AHU, Moçambique, caixa 134, doc.61-A, 26.11.1810.

89 AHU, Moçambique, caixa 144, doc.94, 1.8.1813.

90 Augusto Lima Júnior, História da Inconfidência de Minas Gerais, 1955, p.283.

91 Joaquim de Montezuma de Carvalho, "Gonzaga na ilha de Moçambique”, Suplemento Literário Minas Gerais(SLMG), n.256, p.7, 24.7.1971.

92 Idem, "Novos dados sobre Gonzaga na ilha de Moçambique", SLMG, n.259, 14.8.1971.

93 AHU, Moçambique, caixa 141, doc.18, 24.9.1812.

94 AHU, Moçambique, caixa 135, doc.12, 3.6.1811. 
Referências

Fontes manuscritas

Arquivo Histórico Ultramarino (Lisboa)

a) Conselho Ultramarino, códice 1349.

b) Seção de Minas Gerais, caixa 135.

c) Seção de Moçambique, caixas 72, 75, 120, 121, 122, 139, 134, 140, 141 e 213.

d) Seção do Rio de Janeiro, Avulsos, caixa 142.

Arquivo Histórico de Moçambique

Códice 11-4483.

Arquivo Nacional do Rio de Janeiro

Códice 5, v.1 e 4.

Arquivo Público Mineiro (Belo Horizonte)

a) Seção Colonial, códice 241 .

b) Secretaria do Governo, caixa 17.

Biblioteca Nacional de Lisboa

Coleção Pombalina, miscelânea 643.

Biblioteca Pública Municipal do Porto

Códice 588.

Fontes impressas

ARAÚJO, J. de S. A. P. et al. Tricentenário de Parati-noticias históricas. Rio de Janeiro: Publicações do Patrimônio Histórico e Artístico Nacional, 1960.

AUTOS DA DEVASSA da Inconfidência Mineira. 2.ed. Anotações de Herculano Gomes e Tarquínio J. B. de Oliveira. Brasília: Câmara dos Deputados; Belo Horizonte: Governo do Estado de Minas Gerais, 1976-1978, 1981-1983. 10v.

BONIFÁCIO, J. A fazenda Borda do Campo: o inconfidente José Aires Gomes. Revista do Arquivo Público Mineiro, Belo Horizonte, ano 11, 1906-1907.

CARVALHO, J. de M. de. Gonzaga na ilha de Moçambique. Suplemento Literário Minas Gerais, Belo Horizonte, n.256, 24 jul. 1791.

Novos dados sobre Gonzaga na ilha de Moçambique. Suplemento Literário Minas Gerais, Belo Horizonte, n.259, 14 ago. 1971.

CUNHA, S. S. da. (Pe.) Antiguidades históricas da ilha de Moçambique e do litoral fronteiro, desde os tempos da ocupação. Lisboa: s. n., 1939.

ENNES, A. De Lisboa a Moçambique. Serões, Lisboa, v.1, n.3; v.1, n.4; v.2, n.7; v.2, n.9, 1901-1902.

GONÇALVES, A. Gonzaga, um poeta do Iluminismo. Rio de Janeiro: Nova Fronteira, 1999. 
GONZAGA, T. A. Obras completas. São Paulo: Cia. Editora Nacional, 1942. . Cartas chilenas. Org. Joaci Pereira Furtado. São Paulo: Cia. das Letras, 1995.

KIDDER, D. P. Reminiscências de viagens e permanência no Brasil, Rio de Janeiro e província de São Paulo. In: ARAÚJO, J. de S. A. P. et al. Tricentenário de Parati-notícias históricas. Rio de Janeiro: Publicações do Patrimônio Histórico e Artístico Nacional, 1960.

LAPA, M. R. (Pref. Org.). Obras completas de Tomás Antônio Gonzaga. Rio de Janeiro: Instituto Nacional do Livro, Ministério da Educação e Cultura, 1957.

LOBATO, A. A ilha de Moçambique. Lourenço Marques: Imprensa Nacional, 1945.

LIMA, O. Dom João VI no Brasil. Rio de Janeiro: Topbooks, 2006.

LIMA JÚNIOR, A. de. História da Inconfidência de Minas Gerais. Belo Horizonte: Itatiaia, 1968.

MAXWELL, K. A devassa da devassa. Rio de Janeiro: Paz e Terra, 1978.

. Conjuração mineira: novos aspectos. Estudos Avançados, São Paulo, v.3, n.6, maio/ago. 1989.

MENDES, F. da C. Catálogo cronológico e histórico dos capitães-generais e governadores da província de Moçambique desde 1752, época de sua separação do governo de Goa, até 1849. Lourenço Marques: Imprensa Nacional, 1892.

OLIVEIRA, T. J. B. de. Cartas chilenas - fontes textuais. São Paulo: Referência, 1972.

REVISTA DO INSTITUTO HISTÓRICO E GEOGRÁFICO BRASILEIRO. Rio de Janeiro, v.8, t.8, 1881.

SANTOS, J. dos. Etiópia Oriental. Lisboa: Biblioteca de Clássicos Portugueses, 1891. v.l.

SANTOS, L. J. dos. A Inconfidência Mineira - papel de Tiradentes na Inconfidência Mineira. São Paulo: Escola Profissional do Liceu Coração de Jesus, 1927.

SILVA, J. N. de S. História da Conjuração Mineira. Rio de Janeiro: Imprensa Nacional, 1948.

WOODHEAD, C. Natal a Moçambique. Porto: Tipografia da Empresa Literária, 1895.

Adelto Gonçalves é doutor em Literatura Portuguesa pela USP e autor de Gonzaga, um poeta do Iluminismo (Nova Fronteira, 1999), Barcelona brasileira (Nova Arrancada, 1999; Publisher Brasil, 2002) e Bocage - o perfil perdido (Caminho, 2003).

@-adelto@unisanta.br

Recebido em 12.5.2009 e aceito em 30.9.2009. 
